\title{
Algumas reflexões por ocasião dos 10 anos do MERCOSUL*
}

\author{
Dr. Augustin Espinosa-Lloveras ${ }^{* *}$
}

Os discretos festejos dos primeiros dez anos do Tratado de Assunção e a situação gerada a partir da recessão na Argentina, coincidiram para marcar uma etapa importante no processo de integração do MERCOSUL, que está sendo avalizada com extremo cuidado por parte dos governos dos quatro países e por nossas sociedades no conjunto.

Nos últimos meses as manchetes dos principais jornais do Brasil, Argentina e Uruguai, apresentavam uma visão apocalíptica do processo: "O fim de um sonho", "Mercosul, uma morte anunciada", etc.

O fato é que depois de quase sete anos de crescimento ininterrupto dos intercâmbios entre os quatro sócios e com um aumento na importância da participação nos mercados, ao final de 1998 se ingressou numa etapa de contração econômica. Esta contração teve origens extra-regionais e agravou-se pela desvalorização do real no Brasil no início de 1999. O novo alinhamento da paridade cambial, resultado de uma decisão da política econômica do Brasil, teve impacto nos fluxos comerciais e gerou a primeira crise de importância no processo.

Reconhecendo alguns destes problemas, se iniciaram tímidos trabalhos em matéria de seguimento da conjuntura e de coordenação de políticas macroeconômicas, os quais têm avançado consideravelmente nos últimos tempos.

Concomitantemente, com a reativação no Brasil no ano 2000, se trabalhou no que chamouse a agenda de relançamento com o objetivo de dar novo impulso ao processo em todas as frentes e, em verdade, se alcançaram alguns progressos. Entretanto a situação na Argentina que todos conhecemos, tem provocado uma reversão grave no processo.

Esta situação regional, em especial devido a crise na Argentina e a desaceleração da atividade econômica no Brasil, apresenta hoje um importante obstáculo ao processo de integração, mais certamente não representa 0 fim do mesmo, nem seu congelamento.

Não vale a pena aqui enfatizar o estado atual do MERCOSUL que é conhecido por todos. Mas, é um fato, estamos frente à crise mais importante que nos toucou viver desde a sua criação. É difícil abstrair-se do "clima de crise"

* Palestra proferida no Programa de Pós-Graduação em Direito da UFRGS, em 08 de agosto de 2001. De gravação e publicação autorizada pelo autor. As opiniões aqui defendidas, são pessoais e não refletem necessariamente as posiçōes do Governo Uruguaio.

** Embaixador do Uruguai. Professor da Faculdade de Direito de Montevideo, (Licenciatura em Relações Exteriores) 
que flutua hoje sobre o MERCOSUL, para avaliar os dez anos da sua existência, pois pode-se perder a objetividade na análise dos benefícios $\mathrm{e}$, o que é mais grave, exagerar o pessimismo ao fazer previsões sobre o futuro do mesmo.

Tentando fazer uma avaliação objetiva, eu diria que, desde o ponto de vista econômico, existem razões para afirmar com conviç̧ão, que o MERCOSUL é um êxito. O MERCOSUL tem sido uma resposta para o problema de acesso ao mercado, quando o mercado internacional não estava gerando o acesso adequado a nossos exportadores, pelo menos nas condições atuais. Tem sido, também, um mecanismo para melhorar a competitividade de nossas economias, o que nos tem permitido uma melhor inserção no mercado internacional, apesar dos protecionismos ainda reinantes. Também tem gerado um impacto nas correntes diretas de investimentos estrangeiros, junto com os processos de abertura econômica e comercial que os quatro países tem levado adiante. Isto conduziu a um processo de modernização das economias dos quatro, algo que teria sido mais difícil de fazer isoladamente.

Como exemplo do que o MERCOSUL tem significado na economia do menor sócio que é meu país, desejo ressaltar que durante estes dez anos, a economia uruguaia cresceu quase $40 \%$ as exportações de bens e serviços aumentaram $80 \%$ e as importações $170 \%$. No triênio 1988/1990, prévio à assinatura do Tratado de Assunção, Uruguai exportou 1.560 milhões de dólares anuais, e uma década depois houve um incremento superior a 50\%. Se excluirmos o MERCOSUL, o crescimento das exportações teria alcançado somente $10 \%$.

Outro elemento positivo é o fato de que as administrações e os negociadores dos quatro países começaram a trabalhar em conjunto e a se conhecer, num processo de aprendizado mútuo e na busca de objetivos comuns, o que também é de importância crucial num projeto de integração.

Revista da Faculdade de Direito da UFRGS, v. 21, Março/2002
Não podemos esquecer que se negociaram importantes Acordos de Associação que vinculam o Chile e a Bolívia ao MERCOSUL. Paralelamente se iniciou um processo similar com a CAN e com o México. Nesse sentido, o MERCOSUL tem sido, e continua sendo um fator dinamizador da integração latino-americana.

Estimamos que estas são respostas importantes, que tiveram um impacto profundo nos quatro países e que devem ser preservados neste momento de crise e revisão.

Neste aspecto, quero deter-me brevemente no caráter essencial do MERCOSUL, como um projeto de elevado sentido histórico, político e estratégico, entre quatro nações do Cone Sul. Como tal, o Tratado de Assunção consagra em primeiro lugar, um esquema de cooperação entre seus sócios com o objetivo final de alcançar um grau importante de integração, depois da recuperação da democracia na região. Para alcançar esse. objetivo, foram criadas instituições e adotado mecanismos jurídicos de solução de controvérsias, acordes, nesta etapa, com a cooperação entre os Estados, mais que os próprios de um esquema de integração purista e abstrato. Conseqüentemente, a composição dos órgãos está nas mãos dos Governos, as denúncias são implantadas pelos mesmos e, fundamentalmente, o controle de seu cumprimento corresponde também eles. Tudo isso não é, em nossa opinião, depois destes 10 primeiros anos, uma deficiência do sistema, senão conseqüência de uma etapa na evolução de um processo de cooperação política entre Estados, na direção de um processo de integração econômica mais ambicioso.

É por isso que acreditamos que é bom que a integração governamental entre os sócios se produza assim de cada Governo tenha priorizado os seus próprios interesses e os de seus setores produtivos e sociais, pela necessidade comum de aperfeiçoar a união aduaneira. E se é verdade que a última nem sempre coincide com os primeiros, entendemos que não há outra forma de avançar no processo, levando em conta a gênese do mesmo, o marco histórico-político no qual está crescendo e as conjunturas internas de cada sócio. Forçar este mecanismo é tão estéril quando impensável.

Desejo enfatizar que a integração não pode ser considerada desde um ponto de vista estritamente comercial ou de produtos, é muito mais importante que isto.

Neste sentido, eu quero lembrar a vocês que em matéria de infra-estrutura e serviços, estamos assistindo a um processo extraordinário na região, nos basta pensar nos temas de integração energética que têm e terão um enorme impacto na vida diária de todos os habitantes e na atividade econômica em geral. Fica, entretanto, muito para ser feito nesta área, para enfrentar melhor a crise como a energética que hoje afeta o Brasil.

Finalmente, desde o ponto de vista político, não temos que esquecer que o MERCOSUL tem servido também de firme âncora ao processo democrático na região, impedindo desbordes e situações que poderiam ter levado, em alguns casos, à ruptura institucional. Somente a instituição da chamada cláusula democrática, por si só, justificaria todo o processo e todos os esforços empreendidos até agora.

Em resumo, um processo de integração desta envergadura não se pode dar em forma totalmente harmoniosa sem discussões ou problemas. O processo da União Européia é um exemplo disto. Não é possível pensar que não existam problemas.

A situação da Argentina, no entanto, apresenta um giro no processo provavelmente em outra direção, ao menos temporariamente, e requererá um grande esforço para determinar para onde se dirige o bloco, como eu já disse antes.

Faremos agora algumas reflexões sobre as novas encontrar novamente seu sentido estratégico.

Em primeiro lugar, nos referiremos aos aspectos jurídicos e institucionais, tão discutidos e questionados.

A questão jurídica continua sendo o grande desafio. Mas não esqueçamos que o processo de integração, seja qual for o modelo escolhido, é uma sucessão de providências jurídicas, na medida que a vontade política esteja acorde com as limitações dos ordenamentos normativos nacionais. Os Estados Parte podem reflexionar sobre a conveniência ou não, de dotar-se de órgãos supranacionais ou intergovernamentais, sem optar necessariamente o exclusivamente por uma ou outra hipótese.

Porém segundo nossa opinião, o grande desafio jurídico do MERCOSUL como processo de integração, continua sendo ainda o regime de incorporação do acervo normativo, seja o que diz respeito à produção do MERCOSUL seja respeito da elaboração de documentos jurídicos entre os Estados Parte.

Com certeza, o regime dualista da incorporação de normas previsto nas Constituições nacionais dos Estados Parte, revela, no estado atual, uma grande apreensão, porque cria um descompasso muito grande entre a elaboração da norma MERCOSUL e sua validade e eficácia no plano interno de cada país.

Nesse sentido, a questão contempla a seguinte ordem de preocupação: a primeira, no plano da reciprocidade de direitos e obrigações, enquanto a norma não esteja vigente concomitantemente em todos os Estados Parte; e a segunda, com relação à obrigatoriedade de sua observância no plano interno e internacional.

Paraguai e Argentina, em suas reformas constitucionais de 1992 e 1994, já deram esse grande passo, sem poder, contudo, resolver 0 problema de forma definitiva. 
Em síntese esta salto qualitativo deve ser estimulado no plano interno de cada país, porque o eixo da discussão não está no plano das relações internacionais senão especial principalmente, no terreno constitucional. Em outras palavras, o futuro do marco institucional do MERCOSUL começando pelo regime de incorporação de normas, não é uma questão que possa ser resolvida à luz da experiência de outros modelos de integração ou da Convenção de Viena de Direito dos Tratados, senão do Direito Constitucional de cada Estado Parte.

Em resumo, o momento histórico para a renúncia parcial das soberanias nacionais no MERCOSUL não chegou ainda. Um lento, porém seguro, avanço do processo de integração, baseado, como dizia o Chancele Lafer, na "criação de confiança" entre seus membros (confidence building), é a única via legítima para lograr esses câmbios culturais necessários em cada sócio, que se traduzirão progressivamente num trânsito natural, desde a reforma de nossas constituições no que tem ver com a internação dos acordos internacionais, até alguma forma com características supranacionais - que todos achamos necessária - mas que não é, hoje condição sine qua non para a conformação de um processo de integração econômica, senão uma condição para seu aperfeiçoamento.

Finalmente, não esqueçamos que em 1991, se desenhou um Tratado de Assunção que não foi concebido como um texto fechado e concluso.

Ao contrário, foi concebido como um tratado preliminar, que organiza uma estrutura institucional e orgânica provisória e deixa aberto o caminho para seu aperfeiçoamento e desenvolvimento. Este aperfeiçoamento, que também inclui o progresso institucional, será o resultado também dessa "cultura da integração" dos Estados Parte, que não admite modelos nem pressões, além das que determinam suas próprias experiências vividas no decorrer $\mathrm{da}$ administração de um processo tão dramático - no bom sentido da expressão - como é o da cooperação e da integração regional, a partir do isolamento e a desconfiança recíproca. Porque não devemos esquecer que essa era a situação dos nossos países até fins da década de oitenta.

Essa "cultura da integração" de que eu falava passa pela substituição de políticas nacionais por políticas compartidas, e esse processo não é obra de negociadores diplomáticas unicamente, senão de todos os atores da sociedade civil: acadêmicos, parlamentares, formadores de opinião, de cada um de nós.

Nesse sentido, enfatizar na educação e na cultura dos cidadãos do MERCOSUR, é uma tarefa prioritária. Sempre lembro do que dizia Mauríce Schumann referindo-se à construção européia. da qual foi um dos artífices: "Si eu tivesse que começar de novo, começaria pela educação e a cultura".

- Outro aspecto importante a encarar seriamente é o da coordenação macroeconômica. Destaco este ponto porque nesta etapa os problemas macroeconômicos tem provocado um grave impacto sobre o processo comercial deteriorando sua marcha e impedindo de avançar nos aspectos de coordenação macroeconômica que no futuro derivariam, talvez, na criação de uma moeda comum. Existem contradições internas entre os quatro devido aos instrumentos utilizados, que dificultam seriamente $o$ avanço neste ponto.

A necessidade de arbitrar mecanismos de controle monetário entre os sócios é uma responsabilidade urgente e iniludível. Hoje, os instrumentos cambiais aplicados por alguns sócios constituem barreiras ao comércio intrazona, impossíveis de franquear.

- Finalmente, assinalo algumas outras definições urgentes que, no meu ponto de vista, requer o MERCOSUL
- Em primeiro lugar, destaco que, para um país menor como o Uruguai, os problemas existentes, hoje, no acesso ao mercado para uma produção pouco diversificada e voltada à exportação, não estão justificando o esforço de ajuste realizado que, vele recordar, foi muito importante e com um elevado custo político.

- Em segundo lugar, a falta de regulamentações adequadas em matéria de políticas públicas, que distorsionam a competência e os regimes de incentivos existentes, mais os problemas de acesso ao mercado já mencionados, geram desequilíbrios nas correntes de investimentos entre os quatro, que dificultam enormemente o processo, ao gerar percepções negativas sobre a distribuição dos benefícios do mesmo.

- Em terceiro lugar temos que incentivar muito mais os investimentos intra MERCOSUL e integrar as cadeias produtivas entre os quatro parceiros.

- Em quarto lugar, a nova etapa requererá definições, imaginação e capacidade de liderança em particular da economia mais importante, devendo-se responder a novas e importantes perguntas: Qual será a direção do novo processo? Manterá-se o objetivo de UA ou se preferirá trabalhar sobre uma ZLC? Como se ajustarão as instituições a este novo conceito ou objetivo? Como se trabalhará na negociação com outros blocos? Isto implicará numa posição debilitada frente ao ALCA? Como se enfrentará a negociação com a União Européia no único mecanismo bloco a bloco existente? A urgência da agenda externa do MERCOSUL, obriga a adotar decisões nesta área, onde nosso processo tem gerado uma "imagem de marca" no mundo.

A Cúpula de Assunção realizada no 22 de junho passado, foi um encontro importante e deu resposta a várias destas questões. Nela os Presidentes do MERCOSUL reafirmaram seu compromisso com a construção do Mercado Comum do Sul e a importância do processo como um instrumento essencial para promover a democracia representativa, o desenvolvimento econômico e a equidade social na região significando na história recente, a mais importante definição estratégica dos quatro países.

Ao mesmo tempo a reunión de Cúpula de Assunção foi uma demonstração de pragmatismo. Reconhecendo os problemas conjunturais e os estruturais que o processo está enfrentando conseguiu ter a flexibilidade necessária para incorporar estes problemas e ir administrando-os. A flexibilidade num processo de integração desta natureza é um elemento essencial. Sem flexibilidade este tipo de processo não pode adaptar-se às circunstâncias cambiantes e voláteis e por tanto não está em condições de absorver e resolver os desafios. Um elemento crucial éa revisão do Arancel Externo Comum do MERCOSUL e nesta reunião deu-se um impulso fundamental a estes trabalhos no sentido de que é um instrumento que deve adequar-se permanentemente às necessidades da inserção competitiva do bloco e dos quatro países no mercado internacional.

Outro elemento relevante do processo foi a implementação das primeiras iniciativas em matéria de infraestrutura originadas da Reunião de Presidentes da América do Sul em agosto de 2000 com o lançamento formal do Eixo de Integração MERCOSUL - Chile, tema que os quatro presidentes mencionam especificamente no Comunicado Conjunto emanade da Cúpula.

Um dos elementos mais importantes resultante dessa Cúpula refere-se ao relacionamento externo do MERCOSUL. Em primeiro lugar deve-se destacar a decisão de iniciar contatos com os EE.UU para explorar a possibilidade de um Acordo $4+1$, no marco do chamado Rose Garden Agreement. Esta é uma iniciativa de grande importância porque permite reativar este acordo marco e explorar com os EEUU a possibilidade de chegar a um Acordo de Livre Comércio que confirmaria o MERCOSUL como o primeiro interlocutor dos EEUU na América. 
Neste sentido se decidiu conceder um mandato à Presidência Pro Tempore do MERCOSUR, agora exercida pelo Uruguai, para convocar o Conselho Consultivo sobre Comércio e Investimentos previsto no Artigo do Acordo assinado entre os Estados Partes do MERCOSUL e o Governo dos Estado Unidos da América, em 19 de junho de 1991 com o objetivo de examinar a possibilidade de iniciar negociações bilaterais no formato $4+1$, dirigidas a melhorar o acesso a mercados. Outrossim, decidiu-se organizar um Grupo Negociador integrado por um negociador em tempo integral de cada Estado Parte e presidido por um coordenador, mecanismo inédito até o presente no MERCOSUL.

É também necessário destacar a importância da reunião MERCOSUL - União Européia realizada em Montevidéu em julho passado. Nesta reunião a UE deu um passo substancial para o processo negociador entre ambos blocos, com a apresentação de uma oferta de acesso a mercado que abrange todo o universo de produtos, incluindo os produtos agrícolas. O significado da apresentação desta oferta vai além da negociação porque é feita num momento de crise muito séria na Argentina e consequentemente representa um gesto de respaldo político ao processo de grande importância, porque o MERCOSUL deve negociar com a UE como bloco. A apresentação desta oferta, para a qual o MERCOSUL deverá dar resposta no máximo até o mês de outubro, adianta consideravelmente o processo de negociação, levando-o inclusive a uma etapa mais avançada que a do próprio ALCA.

Um último ponto vinculado com a situação da Tarifa Externa Comum após a Cúpula de Assunção. Como é de conhecimento, posterior à Resolução nro. 258 da Argentina reduzindo a tarifa para bens de capital e outros produtos, Paraguai também realizou modificações na TEC (aumento 10\% incluido comércio intra MERCOSUL) e Urugua aumentou a taxa estatística para 3\% incluindo o

comércio intra comunitário. No final de julho Brasil decidiu reduzir as tarifas para mais de posições arancelarias no setor químico e farmacéutico. Considerando estas medidas, os quatro Presidentes do MERCOSUL, reunidos em forma extraordinária em Lima (por ocasião da posse do Presidente Toledo), deram novamente uma demonstração de pragmatismo aprovando as modificações realizadas em forma unilateral na TEC até agora e decidindo que no futuro nenhuma modificação poderá ser feita em forma unilateral.

Como reflexão final, diria que os processos de integração passam, durante sua evolução, por problemas externos e internos que afetam seus desdobramentos naturais. Foi assim na Europa, especialmente na década dos anos sessenta, e está sendo assim no MERCOSUL hoje, como foi há três anos atrás. Seria surpreendente se o MERCOSUL hoje não apresentasse sinais de fadiga, pela combinação das crises financeiras com os problemas naturais da consolidação e aprofundamento do processo negociador. Quando surgem essas dificuldades, como as que afetaram o Brasil em 1998, ou a Argentina este ano, as contradições. que sempre existiram, entre as medidas de política econômica, sejam de índole monetária, fiscal ou tarifária, adotadas em conjunto pelo MERCOSUL, passam a ter uma visibilidade maior. Esta realidade faz aumentar, no exterior $\mathrm{e}$ em círculos domésticos também, as incertezas em quanto ao futuro e inclusive à sobrevivência do que, acredito ainda, é hoje a ação com mais êxito da política externa de Argentina. Brasil, Paraguai e Uruguai.

Frente à vitalidade que o Embaixador do Rego Barros chamara dos "anos mágicos do MERCOSUL" entre 1991 e 1998, tem que se entender o desencanto dos últimos três anos. Isto somente pode superar-se com crescimento, porque somente o crescimento produzirá um câmbio na opinião pública e no empresariado. Como dizia outro grande diplomata brasileiro, $o$ Embaixador Rubens Barbosa, para enfrentar as crises do MERCOSUL, é preciso mais MERCOSUL. Eu falaria de mais e melhor MERCOSUL. E isto é o que provoca a tentação de buscar o crescimento fora de um MERCOSUL, hoje quase fora dos trilhos. Se não há crescimento aqui, vamos busca-lo noutro lugar. Aí aparece o sonho da ALGA e, como diz do Rego Barros, quando se compara uma realidade com um sonho, é o sonho que termina ganhando. Mais acredito que é melhor enfrentar a realidade ... e sonhar menos....

Hoje, nós que vivemos este processo desde seu nascimento, nos encontramos afortunadamente, numa postura que expressa uma dicotomia entre fidelidade e crítica, de oposição entre um cego dogmatismo e um necessário pragmatismo realista, de confrontação de ilusões exageradas, com a necessária assimilação de verdades objetivas. E por isso que acredito que este é um bom momento para redefinir o MERCOSUL.

E não tenho encontrado melhor redefinição que a proposta recentemente pelo Chanceler Celso Lafer num artigo de imprensa, com motivo de comemorar os 10 anos do MERCOSUL.

Diz o Chanceler que o MERCOSUL é "um espaço de paz e segurança para a construção consensual e a aplicação de normas jurídicas de solução de conflitos e promotoras de cooperação". Repito: "um espaço..."

Com esta definição voltamos ao espírito do Preâmbulo do Tratado de Assunção, tão esquecido mais tão vigente. E conveniente recordar alguns elementos aí recolhidos, que são a essência do processo de integração, tais como: que "a integração constitui condição fundamental para acelerar (nossos) processos de desenvolvimento econômico com justiça social"; que "esse objetivo deve ser alcançado... preservando o meio ambiente, $o$ melhoramento das interconexões físicas, a coordenação de políticas macroeconômicas e da complementação dos diferentes setores da economia"; a "necessidade de promover o desenvolvimento científico e tecnológico dos Estados Partes, ... a fim de melhorar as condições de vida de seus habitantes"; e, finalmente, deixar estabelecidas as bases para uma união cada vez mais estreita entre seus povos".

Este MERCOSUL que se vislumbrava no Preâmbulo do Tratado de Assunção éo MERCOSUL que temos hoje que resgatar, sobretudo porque as novas gerações necessitam desses ideais para acreditar nos processos de integração. Os jovens creio que não se enamoram de uma alíquota tarifária, necessitam crer em algo mais, por isso o componente ético deve ser a base de um futuro onde democracia, desenvolvimento econômico e justiça social, sejam os pilares fundamentais de nossas sociedades.

Temos, portanto, senhores e senhoras, que seguir trabalhando. Todos os dias, como há 10 anos, para tornar realidade o único que é importante em todo este processo, que são estes objetivos enunciados no Preâmbulo do Tratado de Assunção.

Muito obrigado. 